\title{
Indications of Paired- vs. Grouped-Peer Feedback on Students' Writing Activities
}

\author{
${ }^{1}$ HCMC University of Information Technology \\ ${ }^{2}$ Van Lang University \\ ${ }^{*}$ Corresponding author. Email: nguyentanloi2802@gmail.com
}

Loi Nguyen Tan ${ }^{1 *}$, Vu Phi Ho Pham²

\begin{abstract}
L2 teachers in Writing have long been using peer feedback to improve their writing skills in the classrooms. While findings from nearly all studies have shown paired-peer feedback and grouped-peer feedback to enhance student writing performance, few studies have attempted to compare the effect of paired and grouped-peer feedback on writing performance. If the results of paired and grouped-peer feedback are thus proposed, the view of using paired and grouped-peer feedback is further clarified in the EFL written guidance, so teachers can have a clearer understanding of the appropriate arrangement for students to receive paired or clustered peer reviews. This helps educators to organize their students in a writing classroom. First, in the current post, we shall address the theoretical basis of peer reviews. We will review previous feedback studies by analyzing paired-peer feedback and grouped-peer feedback behaviors in foreign and Vietnamese contexts. Finally, we will define the research differences based on theoretical review and previous studies.
\end{abstract}

Keywords: Writing activities; Paired-peer feedback; writing performance; grouped-peer feedback.

\section{INTRODUCTION}

International communication has been rising in line with globalization's current trend, resulting in a growing demand for English communication skills. Much professional correspondence is still carried out mainly in writing. This ability is an important component, though many consider it difficult to master than other language skills, i.e., speaking, listening, and reading[1-4]. Hence, a big concern for English learners is how to write well. Students can currently find writing abilities boring and difficult to learn since writing teachers encourage them to work independently. While students make great efforts from practical experience to present their ideas logically and practically as teacher observation, their final writing product still showed errors. This could stem from a lack of opportunities for their teachers or peers to receive instant feedback[5]. In response to this issue, most strategies are recommended to build an atmosphere that allows students to engage with other students. Under these methods, it is possible to give and receive feedback to enable students to write assignments more effectively. As part of teaching and learning practices, this incorporation of feedback provides students with more opportunities to obtain and provide feedback together to satisfy the teacher's demand and improve students' writing. Thus, If feedback is successfully applied in the classroom, it can inspire students, improve their positive attitudes, and develop their writing skills $[6,7]$.

As a second language writing instruction, Peer review has increasingly been used in English and plays an important role in developing student writing skills [810]. Written peer feedback research has found that peers are typically able to give valid comments [9], and their feedback is usually just as good as the feedback of a teacher in helping students improve their drafts [11], sometimes even more effective [12]. The general advantages of peer reviews can come from many sources. First, feedback is understandable that peers can best express [10]. Second, total input than an over-taxed teacher can be given by multi-peer feedback [8]. When several reviewers find the same issues, this practice will help increase more persuasive reviews, and this feedback reflects more diverse views of the audience 
[9]. Third, The process of providing feedback to others[10], learning from good and poor writing techniques, is a learning opportunity itself. In general, arranging peer feedback activities could be one of the most effective ways for learners to improve their writing [13].

Peer reviews can be seen as forming students in pairs or groups. However, the way teachers train students in pairs or groups is not clearly indicated by previous researchers[14,15], which often confuses teachers when performing peer feedback activities. This poses concerns about whether grouping students in two, three, or four will lead to the greatest performance. According to Shehadeh[16], there are essentially two main ways to administer peer feedback in a written classroom: peerto-peer feedback and peer-to-peer feedback.

- Paired-peer feedback refers to bringing two learners into the writing classroom to correct each other's writing tasks and propose recommendations or suggestions on them.

- Grouped-peer feedback: refers to the practice of using a group of three or four students in the writing classroom to correct each other's writing assignments and send them ideas or suggestions about them.

Many peer-to-peer feedback studies have put students in pairs to comment and provide peer feedback, often linked to individual peer feedback. This kind of feedback's positive impact links two students and generates a sense of critical readers and authors [17-19]. While some studies have shown that working in pairs creates more opportunities for individual involvement, other studies have shown that working in input delivery groups also results in better EFL writing results[20, 21] as it provides more effective and legitimate assistance to students[19] and larger groups (e.g., four) to encourage students to take advantage of this opportunity.

The question open to future studies is how the number of students interacting with each other influences the writing product's quality. This suggests that when all three or four group members work together on a written document to make an argument, it implies a better result than only two students do. In fact, there is also a need to analyze the influence of major classes (of three or four students) on writing skills. More learners represent more information and more linguistic capital than a sociocultural perspective. Conflict or disagreement is considered productive when working in groups because students delay agreement and promote more knowledge search $[23,24]$. Students can make statements and give evidence to support them and resolve the dispute when they take different assignments. Students will need to have much more comprehensive arguments for defending their own points of view. Once the conflict has been expanded and clarified, they will build a clearer understanding of the related issues[25,26]. More ideas and problems are addressed in detail as students work in groups to address issues, making them more resourceful to choose solutions and establish a writing standard [27]. There may be a disparity between the effect of peer-to-peer reviews and peer-to-peer feedback on writing outcomes. Therefore, this paper covers the theoretical foundations of peer feedback, discusses the relevant peer feedback studies by looking at paired and clustered peer feedback performed in the international context and the Vietnamese contexts, and finally shows the study gaps based on previous theoretical analysis studies.

\section{LITERATURE REVIEW}

\subsection{Collaborative Learning}

Information among students in the class is co-built and shared. Therefore, learning cannot be an individual activity; it has to be a collective activity[28]. Learning can also not be an independent practice in Dewey's realistic method [29]. Instead, learning includes encouraging students to engage in a social relationship. A person's cognition results from cooperation in social groups and is correlated with social life. In the group sense, Vygotsky [28] primarily concentrated on individuals' influence. Community study in the university setting is strongly recommended to be done in the classroom to plan for future lives, according to Smith et al. [30]. Collaborative learning is essentially a pedagogical activity that allows learners to work together to solve a problem, complete a task, and produce a product. Besides, collaborative learning stresses individual community members' strengths and accomplishments in all classroom circumstances where studBesidestively participating in groups. "Roschelle and Teasley described collaborative learning ([31]; p.70) as "participants' collective participation in a concerted attempt to solve the problem together. Similarly, Webb and Palinscar[32] argued that in a collaborative atmosphere, students work collaboratively to understand each other in the community, offer assistance to others and gain support from others. Several authors contribute to the various perspectives of writing, such as content, organization, as well as language, according to Chao and Lo[33], and also contribute to relieving anxiety about the task's difficulty. Collaborative learning theory is also seen as a sign of peers' provision and receipt of constructive feedback.

The student learns from those with more experience, according to Vygotsky[28]. The Proximal Development Zone (ZPD) refers to the distance between students' willingness to collaborate with their peers without their peers' assistance [28]. ZPD gives students the ability to develop skills such as fear and anxiety. Particularly, 
observing and experiencing people through social class interactions shows how students grow their skills individually.

In a classroom setting, the student can internalize the "expert" problem-solving techniques by interacting with more knowledgeable peers, thereby enhancing their ability to complete assignments [34]. Students may benefit from peer input within the ZPD by transitioning from another control mechanism (i.e., performing with help from others) to self-regulation (i.e., being capable of autonomous problem-solving)[35]. This is very important to one of the key goals of classroom assessment, i.e., encouraging learners to own their own learning and creating learners capable of self-regulating learning. Therefore, student-student interaction is regarded as a way of ZPD in writing classes through feedback implementation.

\subsection{Writing performance}

The ability of students to effectively write a piece and turn thoughts and ideas into written language, according to Sharadgah[36], is not easy at all. In particular, Writing output means "the writing of an idea of the writer in a written form that takes into account an audience and demonstrates the mechanics of a particular subject with a clear organization of ideas, appropriate and relevant content" ([37]; p.2). Two domains, micrograms (grammatic precision and lexical sophistication) and macro levels, test writing output (the coherence and cohesion of writing). Writing skills are known as the macro and microphones[38]. The assessors will create rubrics to write tests and assessments based on these aspects. These dimensions help each other in creating a successful writing skill.

- Micro-level (level of word or phrase): grammatical conventions, spelling, and punctuation[39], appropriate choice of the word[13].

- Macro-level: quality of information, coherence and organization[39], concept development[13].

\subsection{Reviews of Related Literature}

\subsubsection{Previous studies on Paired-Peer Feedback}

Many previous studies have been based on a type of feedback, also known as peer-to-peer feedback, a system where two students share their writings to comment. The findings reported that peer-to-peer feedback was more positive, as this form of feedback increased student engagement and made students more critical of readers and writers.

Kamimura (2006) [40] explored the impact of different English proficiency levels on outcomes and what variations can be predicted based on proficiency levels. Twenty-four students from two university classes participated in the study. Students wrote a pre-test argument. They then wrote a new essay and took on the English paragraph structure. Then a student had a partner assigned and told them to work for the rest of the experiment with their partner. In each passage, they were asked to remember the errors and to suggest solutions to the issues. Students were asked to compose a post-test essay. Second, peer-to-peer input in the essay positively impacted the writing success of both high and low-profile students. Second, even though both students wrote longer essays in the post-test, this activity had no major impact on their fluency. Most peer comments were useful, pertinent to the article, whether the comment was in English or not. Most students have considered the comment helpful. High-level students prefer to make global comments in the debate and are more concrete, whereas low-level students tend to make detailed sentential comments.

In 2008, Xiao [41] studied the extent to which Chinese learners implemented a paired-peer model, how effectively they used it, and how it impacted their performance in English. The intervention research was performed with 30 second-year students from the Shantou Radio and Television University in China. Students had to partake in peer review events but volunteered to participate in peer review sessions. It's performed in pairs, not in groups. Students were allowed to shape and research pairs. They have been academic partners. The results demonstrated peer engagement and eliminated language learning barriers in distance learning. Students indicated that they gained from peer feedback activities on EFL writing.

In 2010, Lam[42] aimed at enhancing students' awareness of skills related to providing consistent and meaningful peer input and helping students use peer-topeer feedback in their writing. Thirty students took part in the research. They sat together to research each other's ideas. The Peer-Peer Review Training has been held for the first three weeks. This session involves modeling, experimenting, and awareness-raising, which enabled the researcher to provide 30 students with adequate training and scaffolding before the peer review operation. An interview was conducted with four 
students about how they responded to the peer review training session. The study suggested that students reacted favorably to peer review in the writing course. Interviews revealed that students who self-criticize their work were much more critical of their own work if they learned how to edit and rewrite their work during peerreview training.

In 2014, Wang [43] explored how students' peer feedback perceptions shift from their EFL writing, the variables that affect their perceived utility of peer feedback for analysis, and their views on peer feedback rubrics. This research included fifty-three Chinese students. The students first learned how to provide input on EFL writing and then partnered up to gain peer feedback. They were partnered with the same partners during the ELF course. After a 20-minute brainstorming session, 40 minutes of writing was assigned. All drafts were circulated to students, and students worked in a paired-peer input session. After reading their first drafts back to the students, they were expected to rewrite them based on peer input. The instructor finally graded the third drafts of the students. Essays, questionnaires, and interviews were used to gather information. The results suggest that students find peer feedback useful for revising the draft. The perceived utility of peer feedback for enhancing language usage may be restricted by limited English proficiency. The students agree that the rubrics are useful to enhance their feedback practice. The analysis has limitations. The study first looked at how students interpret EFL writing through paired-peer feedback. A more detailed study would have had more strength if additional studies had been done with students' writing and teachers' expectations. Second, the sample size was not broad enough to generalize the findings to various contexts. Students collaborate with a consistent partner during the writing course.

In 2017, Kim [44] studied the characteristics of the peer relationship between adult learners in the naturalistic lessons of the EFL. The participants were college students from South Korea. Seven different language tasks have been used to collect data from paired peers. These tasks include filling in blanks, jumbled dialogs, reconstructing text, creating a story, and adding a sentence. Patient and parent transcripts and interview data were analyzed. Students seldom asked their peers to engage in a problem-solving process. The problems were solved individually. Loss of interaction between pairs can negatively affect their learning opportunities. The findings suggest that pair work or peer interaction is a success factor. Interactions such as group work should be done in the classroom to determine this form of peer input accuracy.
In 2018, Zhao [45] analyzed the interactions and similarities to mediation strategies and the volume and concentration of feedback. The study included 18 undergraduates from a large-scale university in southern China. Participants were formed with three different interaction modes: competitive, expert/novice, and dominant/dominant interaction. A 20-minute training session was conducted before each peer review operation to increase the accuracy and quantity of peer reviews. They specialized in peer-to-peer and peer-topeer studies in six genres. Two or three dyad groups were recorded with digital recording pens, depending on the number of volunteers. The findings show that not all feedback worked well because of the variations in interaction styles, the strategies used by mediators to interpret feedback, and the learning opportunities offered by oral feedback. The lack of writers' attempts to negotiate ratings with peer-reviewed reviewers left more space for reviewers to comment.

In the same year with Zhao, Le [46] explored how peerto-peer response was used to provide feedback and determine the efficacy of peer-to-peer response to student writing. The participants were thirty-nine students from the Department of Foreign Languages at Ho Chi Minh City University. The writing course started with the practice of presentation, analysis, and writing. Next, students participated in a training session to write an essay and give input to other students. They were then asked to provide and receive feedback via a guided correction. They were asked to fill out the selfassessment sheet after writing the course. The study found that the participants looked at the structure, the layout of the paper, and the process's most noticeable errors in writing. Students indicated that they should participate in groups to get more input or better ideas on each subject. They asked the other students to concentrate on improving their writing, but not just to point out the wrong pieces.

\subsubsection{Previous studies on Grouped-Peer Feedback}

In addition to paired-peer feedback, some studies have paid attention to the effects of group-peer feedback on student writing outcomes, a process in which students provide peer-to-peer feedback in a group of three or four[19]. Shehadeh ([19]; p.150] suggested that grouppeer feedback is more "reliable and valid" than pairedpeer feedback because peer feedback in group work can offer many learning opportunities. Also, students would play various roles in exploring and experiencing different writing aspects that could improve writing. 
In 2010, Ting and Qian [47] performed a Chinese EFL writing classroom experiment on untrained groupedpeer reviews. Twenty-two students were randomly divided into nine groups, with three to four in each group. The research lasted 16 weeks. Students were invited to read essays written by community members and provide each other with written input for revision. After reading their classmates' editions, the students wrote a second draft. The teacher read and commented on the second draft. Students were reading and writing their third draft. Data was collected on the first and second drafts. The results indicate that students followed many of the community's recommendations, mostly superficial revisions. The revised drafts were slightly better, but they were greatly improved concerning the accuracy. Grouped feedback practices may result in independent self-correcting readers and authors. However, these results cannot be extended to other environments.

In 2012, Yao and Cao [48] published a study on college students' English writing abilities in China. There were 64 students from Minzu University in the first semester of 2010-11. It was expected that students in both groups would write eight posts. Students in the experimental class were formed into groups of four. The t-test was used for an explanation. The quantitative study results showed that students in the treatment class had a higher mean score than control class students. We can conclude that group peer review helps students improve their content and organization writing, which allows them to explore and clarify various ideas about their subjects. This practice also helped students learn from their audience. Lastly, students enjoyed writing an original text that also helped their faith in writing a text. While some students were not pleased with the peer reviews, they did feel that the peer reviews of their written work should be from those who are native speakers. Peer evaluation is innately motivational.

In 2014, Pham and Nguyen [49] performed a quantitative analysis of group peer reviews in writing instruction. Thirty-seven graduate students at HCMC Open University were in the sample. Drafts, group peer suggestions, and revisions were used to assess group peer input impacts. After teaching students to comment on literature, they participated in a writing competition. Students were split into groups of four to five participants, and they were taught to give and receive input. Each student received at least 4 comments from their group members. Results showed that the most common student comments were clarification, suggestion, and description. Grouped-peer feedback participation had a positive effect on the revision process. Students learned assessment, teamwork, and commenting skills by participating in this activity. After taking the course, students looked at mistakes and errors rather than substance and organization. Students only reviewed and updated feedback from their colleagues and did not consider the most useful ones.

In 2016, Yu and Lee [50] studied the techniques writers employed to respond to peers' feedback. Four students in mainland China were selected for this research. The participants had gained English fluency by attending a university or college for at least six years, and at least half a yearA 16-week reading/writing class took place (two hours per week). Community peer reviews, semistructured interviews, inspired recalls, and student writing ideas were used for this study. These students are able to manipulate the use of the implicit rule of the community and the absence of a negative confrontation in the negative part of the problem. They used group input in L2 writing and grouping to control their work. L1 helped to enhance learners' comprehension of the texts and encouraged communication. However, the four students had a good relationship with one another, which affects the results' reliability.

In 2016, Nguyen [51] performed a qualitative study of the current EFL university writing course using a groupbased feedback approach to optimize learning metacognitive awareness and skills. Forty-nine college students took part in the report. All students were presented in-class videos, and eight students in each class were selected for semi-structured interviews. The students went to the English class to take an IELTS writing test. Data were collected in weeks 9 and 10 of the 15-week duration. Interview data showed that students were prepared to write classes in informal groups. Students are only given so many chances to optimize metacognition. Students called for collaborative working and teaching and input in their writing classes. The main explanation for this was that group feedback was poorly enforced and regulated. The way to group students was uncertain. The analysis would have been successful if a larger sample was used. Also, different methods should be used to verify generalizability.

In the same year of 2016, Kurihara [52] investigated the effects of the peer review group's writing skills. Thirtyfive students completed their second year of study in the last year. Pre-test, post-test, delayed post-test, questionnaires, and interviews. First, students were asked to provide effective reviews and then paired to peer review each other's essays. Second, students were grouped into four students, shared the same form of writing the theme to deliver and receive feedback. They 
were able to select their own peers to maximize the number of comments they made. It took 20 minutes for the meeting. The results showed that the students' performance who received feedback from the teacher was higher, while the performance of those who received feedback from peers was not significantly different. There was no substantial difference between the post-test and the delayed post-test.

Pham and Usaha [53] conducted a study to investigate any gaps in revision-based comments between global and local areas. The study included thirty-two secondyear majors in English at a University in HCM City. The students worked in groups of four to provide insight into the two examples of the essays presented. After training in blog comments, students posted their writing papers on their blogs and commented on other students' written papers. Data from student ideas, peer reviews, and in-depth interviews were collected. There have been very few comments in global areas and no qualifying comments in local areas. More comments were given than revisions, suggesting some comments were not replied to. At high levels, student writers needed more help, but they got more peer suggestions on lower-level items such as terms and phrases. The study did not equate e-comments from lecturers with e-comments from peers.

In 2019, Kuyyogsuy [54] used mixed methods to research Thai university students' attitudes toward grouped-peer reviews. The research was performed by 21 undergraduate students in one university in three border provinces of Thailand. 36 questionnaires consisting of a 5-point Likert scale and 6 open-ended items were used to collect the data. The students were taught during the first three weeks on peer feedback tasks. The instructor had the students clarify and identify writing problems, explain and offer advice, follow peer input, and clarify and identify writing problems. Practicing some checklists and four-step procedures were distributed to students. Students wrote a narrative paragraph for two weeks, then engaged in a community discussion of peer reviews. Each student plays two positions, assessor and assessee. They were paired up with one member to listen and respond to the other two. Student findings demonstrated a positive attitude toward grouped-peer input practices, which reached a high level in four domains of the writing process, affective techniques, critical thinking skills, and social interaction abilities. The students' questionnaires showed that when they were in a disagreement with a peer, they could overcome their feelings to stay in the group. They are more accepting of their peers' views than their own. When they completely refused their peers' comments, they conducted negotiations together. The findings showed that students' writing attitudes were influenced by clustered peer feedback practices.

Further research done by Pham [55] has found that peergroup feedback helps many students succeed in writing. Thirty-seven university students took part in the research. Six writing activities have been used to collect data. After the first training session, the students were split into groups to observe and provide comments. They collected group e-comments on their research project, revised their paper, and finally submitted a revised paper with group e-comments for the comments of the lecturer. Students saw something in an e-peer response and developed their skills after using ecomment modeling. Comment pages on blog sites become more global and revision-oriented. Changes were made more often at the word and phrase stages. However, better reporting of the control group vs. experimental group would have improved the analysis.

\section{CONCLUSION}

As discussed above, many previous studies have explored many different issues and aspects of pairedpeer feedback/comments and group-peer feedback/comments to see their effects on students' written papers. These variables included: 1) the influence of informed peer input and group feedback; 2) student behavioral preferences for peer feedback and peer feedback; 3) student beliefs or perceptions about the consequences or benefits of peer feedback and peer feedback. While results from almost every study show a useful and beneficial source of paired-peer feedback and group-peer feedback, few studies have attempted to compare these two kinds of feedback on writing performance. In addition, most studies have been performed in such countries as Japan, Korea, Vietnam, China, Thailand, and Taiwan, etc. However, few studies have been published in Vietnam on peer feedback pairing and peer feedback and writing. The scene of the EFL writing instruction is, therefore, more complete when the effects of peer input and peer feedback are indicated to provide educators with a clearer evaluation of organizing students in the classroom to maximize the benefits of peer feedback and peer feedback. This will allow educators to get a clearer image in the written classroom of their students. 


\section{AUTHORS' CONTRIBUTIONS}

This article draws teachers' attention to the need to employ paired-and grouped-peer feedback into their writing classes. At the same time, paired-and groupedpeer feedback could relieve the EFL teachers' from the heavy burden of giving students feedback in the writing tasks.

\section{ACKNOWLEDGMENTS}

The author would like to gratefully thank his supervisor, Assoc. Prof. Dr. Pham Vu Phi Ho, for the constant support, guidance as well as invaluable constructive feedback, which assisted him in improving this article.

\section{REFERENCES}

[1] J. Defazio, J. Jones, F. Tennant, S.A. Hook, Academic literacy: The importance and impact of writing across the curriculum, Journal of the Scholarship of Teaching and Learning. 10(2) (2010), 34-47.

[2] J. Elander, K. Harrington, L. Norton, H. Robinson, P. Reddy, Complex skills and academic writing: a review of evidence about the types of learning required to meet core assessment criteria, Assessment and Evaluation in Higher Education. 31(1) (2006), 71-90. https://doi.org/10.1080/02602930500262379

[3] J. H. Jahin, An investigation into Saudi EFL major student teachers' perspectives on foreign language anxiety, Journal of Educational Research. 6(11) (2007), 1-79.

[4] J. H. Jahin, M. W. Idrees, EFL major student teachers' writing proficiency and attitudes towards learning English, Um Al-Qura University Journal of Education and Psychology Sciences. 2(2) (2010), 9-73.

[5] J. Hattie, H. Timperley, The power of feedback, Review of Education Research. 77(1) (2007), 81-112. https://doi.org/10.3102/003465430298487

[6] J. C. Richards, C. Lockhart, Reflective Teaching in Second Language Classrooms, Cambridge University Press, USA, 1996.

[7] N. Srichanyachon, Teacher written feedback for L2 Learners' writing development, Silpakorn University Journal of Social Sciences Humanities and Arts. 12(1) (2012), 7-17.

[8] A. B. M. Tsui, M. Ng, Do secondary L2 writers benefit from peer comments?, Journal of Second Language Writing. 9(2) (2000), 147$170 . \quad$ https://doi.org/10.1016/S10603743(00)00022-9
[9] K. J. Topping, A. M. Fisher, Computerised formative assessment of reading comprehension: field trials in the UK, Journal of Research in Reading. 26(3) (2003), 267 279. https://doi.org/10.1111/1467$\underline{9817.00202}$

[10] M. Yang, B. Richard, Z. Yu, A comparative study of peer and teacher feedback in a Chinese EFL writing class, Journal of Second Language Writing. 15 (2006), 179-200. https://doi.org/10.1016/j.jslw.2006.09.004

[11] K. J. Topping, Peer assessment between students in colleges and universities, Review of Educational Research. 68(3) (1998), 249-276. https://doi.org/10.3102/00346543068003249

[12] K.. Cho, C. MacArthur, Learning by reviewing, Journal of Educational Psychology. 103(1) (2011), 73-84. https://doi.org/10.1037/a0021950

[13] K.. Hyland, Second language writing, Cambridge University Press, USA, 2003.

[14] V. Arndt, Response to writing: Using feedback to inform the writing process, in: M. N. Brock, L. Walters (Eds.), Teaching Composition Around the Pacific Rim: Politics and Pedagogy, Multilingual Matter, UK, Clevedon, 1993, pp. 90-116.

[15] J. Liu, J. G. H. Edwards, Peer response in second language writing classrooms, University of Michigan Press, USA, 2002.

[16] A. Shehadeh, One-to-one and group feedback in the L2 writing classroom: Benefits and classroom implementation, in: D. Anderson, C. Coombe (Eds.), Cultivating real writers, HCT Press, Higher Colleges of Technology, UAE, 2010, pp. 109-120.

[17] K. Cho, C. MacArthur, Learning by reviewing, Journal of Educational Psychology. 103(1) (2011), 73-84. https://doi.org/10.1037/a0021950

[18] P. Rollinson, Using peer feedback in the ESL writing class, ELT Journal. 59(1) (2005), 2330. https://doi.org/10.1093/elt/cci003

[19] A. Shehadeh, The effect of group and individual peer feedback on student writing in an EFL Gulf context, in: C. Coombe, L. Barlow (Eds.), Language teacher research in the Middle East, Alexandria, VA, 2007, pp. 147160.

[20] A. F. Dobao, A. Blum, Collaborative writing in pairs and small groups: Learners' attitudes and perceptions, System. 41(2) (2013), 365378. https://doi.org/10.1016/j.system.2013.02.002 
[21] A. F. Dobao, Attention to form in collaborative writing tasks: Comparing pair and small group interaction, Canadian Modern Language Review. 70(2) (2014), 158-187. https://doi.org/10.3138/cmlr.1768

[22] R. Needham, Teaching strategies for developing understanding in science. Children's Learning in Science Project, Leeds, UK, 1987.

[23] R. Burnett, Conflict in collaborative decisionmaking, in: C. Thralls, N. Bryler, (Eds.), The social perspective and professional communication: Diversity and directions in research, SAGE Publications, 1993, pp. 144163.

[24] C. A. Chinn, D. B. Clark, Learning through collaborative argumentation., in: C.E. HmeloSilver, C. A. Chinn, C. K. K. Chan , A. M. O'Donnell (Eds.), International handbook of collaborative learning , Routledge, UK, London, 2013, pp. 314-332.

[25] M. J. Baker, Argumentative interactions, discursive operations and learning to model in science, in: P. Brna, M. Baker, K. Stenning, A. Tiberghien (Eds.), The role of communication in learning to model, Lawrence Erlbaum Associates, Mahwah, New Jersey, London, 2002, pp. 303-324.

[26] E. A. Linnenbrink, P. R. Pintrich, Achievement goal theory and affect: An asymmetrical bidirectional model, Educational Psychologist. 37(2) (2002), 69-78. https://doi.org/10.1207/S15326985EP3702_2

[27] M. M. Nelson, C. D. Schunn, The nature of feedback: how different types of peer feedback affect writing performance, Instructional Science. 37 (2009), 375-401. https://doi.org/10.1007/s11251-008-9053-x

[28] L. S. Vygotsky, Mind in society: The development of higher psychological processes, Harvard University Press, USA, 1978.

[29] J. Dewey, Democracy and education, Free Press, Hazleton, 1997.

[30] G. G. Smith, C. Sorensen, A. Gump, A. J. Heindel, M. Caris, C. D. Martinez, Overcoming student resistance to group work: Online versus face-to-face, Internet and Higher Education. 14(2) (2011), 121-128. https://doi.org/10.1016/j.iheduc.2010.09.005

[31] J. Roschelle, S. D. Teasley, The construction of shared knowledge in collaborative problem solving, in: C. O'Malley (ed.), ComputerSupported Collaborative Learning, SpringerVerlag, Berlin, 1995, pp. 69-197.
[32] N. M. Webb, A. S. Palincsar, Group processes in the classroom, in: D.C. Berliner \& R.C. Calfee (Eds.), Handbook of Educational Psychology, Lawrence Erlbaum Associates, 1996, pp. 841-873.

[33] Y. C. J. Chao, H. C. Lo, Students' perceptions of Wiki-based collaborative writing for learners of English as a foreign language, Interactive Learning Environments. 19(4) (2009), 395411. https://doi.org/10.1080/10494820903298662

[34] R. Donato, Collective scaffolding in second language learning, in: J. P. Lantolf \& G. Appel (Eds.), Vygotskian approaches to second language research, Ablex Publishing Corporation, N.J, 1994, pp. 33-56.

[35] O. S. Villamil, M. C. M. de. Guerrero, Sociocultural theory: A framework for understanding the social-cognitive dimensions of peer feedback, in: K. Hyland \& F. Hyland (Eds.), Feedback in second language writing: Contexts and Issues, Cambridge University Press, USA, 2006, pp. 23-41.

[36] T. A. Sharadgah, Writing in an Internet-based environment: Improving EFL students' writing performance through text-based chat, International Journal of Humanities and Social Science. 3(14) (2013), 258-266.

[37] M. Mohammed, Using Wikis to develop writing performance among prospective English as a foreign language teacher, 2010. Retrieved from http://www.nauss.edu.sa/acit/PDFs/f1766.pdf

[38] H. D. Brown, Teaching by principles: An interactive approach to language pedagogy, Longman, 2007.

[39] P. Ur, A course in language teaching practice and theory, Cambridge University Press, UK, 1996.

[40] T. Kamimura, Effects of peer feedback on EFL student writers at different levels of English proficiency: A Japanese Context, TESL Canada Journal. 23(2) (2006), 12-39. https://doi.org/10.18806/tesl.v23i2.53

[41] J. Xiao, Paired peer review in a distance-taught EFL writing course, The Journal of Asia TEFL. 5(4) (2008), 88-115.

[42] R. Lam, A peer review training workshop: Coaching students to give and evaluate peer feedback, TESL Canada Journal. 27(2) (2010),

114-127. https://doi.org/10.18806/tesl.v27i2.1052 
[43] W. Wang, Students' perceptions of rubricreferenced peer feedback on EFL writing: A longitudinal inquiry, Assessing Writing. 19 (2014), 80-96.

[44] Y. Kim, The nature of peer interaction: Role relationships formed in pair interaction, English Teaching. 72(1) (2017), 131-158. https://doi.org/10.15858/engtea.72.1.201703. $\underline{131}$

[45] H. Zhao, New insights into the process of peer review for EFL writing: A process-oriented social-cultural perspective, Learning and Instruction. 58 (2018), 263-273. doi:10.1016/j.learninstruc.2018.07.010

[46] L. H. T. Quyen, Peer-correction in responding to writing as work in progress: A way to improve the management of writing in the classroom, in: Language Teaching and Learning Today, Diversity and unity of language education in the globalized landscape, Ho Chi Minh City, Vietnam, 2018, pp.228-241.

[47] M. Ting, Y. Qian, A case study of peer feedback in a Chinese EFL writing classroom, Chinese Journal of Applied Linguistics. 33(4) (2010), 87-98.

[48] C. Yao, H. Cao, How peer-review affects Chinese college students' English writing abilities, Theory and Practice in Language Studies. 2(3) (2012), 554-559. https://doi.org/10.4304/tpls.2.3.554-559.

[49] V. P. H. Pham, D. T. T. Nguyen, The effectiveness of peer feedback on graduate academic writing at Ho Chi Minh City Open University, Journal of Science Ho Chi Minh City Open University. 2(10) (2014), 35-48. https://doi.org/10.46223/HCMCOUJS.soci.en .4 .2 .320 .2014

[50] S. Yu, I. Lee, Exploring Chinese students' strategy use in a cooperative peer feedback writing group, System. 58 (2016), 1-11.

[51] T. H. Nguyen, Peer feedback practice in EFL tertiary writing classes, English Language Teaching. 9(6) (2016), 76-91. https://doi.org/10.5539/elt.v9n6p76

[52] N. Kurihara, Do peer reviews help improve student writing abilities in an EFL high school classroom?, TESOL Journal. 8(2) (2016), 450-470. https://doi.org/10.1002/tesj.282

[53] V.P.H. Pham, S. Usaha, Blog-based peer response for L2 writing revision, Computer Assisted Language Learning. 29(4) (2016), 724-748. https://doi.org/10.1080/09588221.2015.10263 $\underline{55}$
[54] S. Kuyyogsuy, Students' attitudes toward peer feedback: Paving a way for students' English writing improvement. English Language Teaching. 12(7) (2019), 107-119. https://doi.org/10.5539/elt.v12n7p107

[55] V. P. H. Pham, The effects of lecturer's model ecomments on graduate students' peer ecomments and writing revision, Computer Assisted Language Learning. (2019), 1-34. https://doi.org/10.1080/09588221.2019.16095 21 